place in "Les Houches" from 5-16 September. We offered two topics:

- origin, structure and evolution of galaxies,

- methods and tools of astronomical observation.

The first was more fundamental, and the second more methodological. We plan to retain this scheme for our future schools, since it gives to each student both a major and a minor theme of interest, and keeps the scope of the teaching broad enough.

The School resources came 26\% from European funds (EEC programme, and European Council) and $74 \%$ from national contributions raised by Network members. All contributions were included in a global budget regardless of their origin. Good financial conditions were offered by the Board (Conseil d'Administration) of Les Houches "Ecole de Physique", in view of the wish of this Board to develop a pre-doctoral school.

Since the spirit of the School was to foster interaction, lecturers were asked to be present as much as possible during the School. Four stayed 2 weeks, four 1 week, one half a week. Springer Verlag (Heidelberg) are publishing a book based on the School material designed to become a series. The $1989 \mathrm{School}$ is planned be held in Ponte de Lima (Portugal) from 11-24 September 1989. The topics will be late stages of stellar evolution and numerical hydrodynamics in astrophysics.

\title{
Physical Mechanisms in Polymer Failure
}

\section{H.H. Kausch and W.J. Cantwell, Lausanne}

\author{
Report on the 20th Europhysics Conference on Macromolecular Physics/ \\ 3rd Lausanne Polymer Meeting, 26-30 September 1988, Lausanne.
}

For the first time in its 16 years of existence, the Europhysics Conference on Macromolecular Physics was held in Switzerland and following the tradition of the Lausanne Polymer Laboratory "Physical Mechanisms in Polymer Failure" was chosen as the conference theme. This topic was viewed from all possible levels and directions, ranging from the molecular scale of small deformations to the macroscopic behaviour of fibre-reinforced composites.

The general theme was subdivided into seven topics:

- Molecular Mechanisms and Theory of Deformation of Polymers

- Micromechanics of Crazing

- Crazing and Fracture

- Fracture and Degradation

- Highly Oriented Fibres

- Polymer Blends

- Fracture of Composites.

Within these subject areas, 30 invited lectures and ensuing discussions covered major recent developments.

\section{Physics of Macromolecules}

The powerful tool of neutron scattering was detailed by $M$. Dettenmaier (Mainz) who showed that the deformation of a molecule (of polycarbonate) is an affine image of the macroscopic deformation at temperatures up to $120^{\circ} \mathrm{C}$. The large molecular anisotropy, there- fore, plays a specific role only close to the glass transition temperature $T_{\mathrm{g}}$ (at $140^{\circ} \mathrm{C}$ ). B. Jasse (Paris) continued this theme and reported an unexpected finding: the first step in the plastic elongation of a sample at the yield point is a slight shortening of the chains by an increase in the number of gauche bonds - interpreted as being due to a shift in thermal configurations equilibrium.

As opposed to the previous discrete molecular approaches, C. G'Sell (Nancy) derived continuum mechanical constitutive equations, linked however, to molecular interpretations. Noteworthy, was the definition of micro-shear domains enlarged by plastic cycling and which favour local molecular mobility. Such a model permits the quantitative description of "rejuvenation" and "physical aging" phenomena.

The above considerations concern molecular segments; they are generally restricted to the range of linear viscoelastic behaviour. All strength properties depend, however, on the nature of the interaction of whole chains, of their interdiffusion and entanglement. $M$. Tirrell (Minneapolis) treated the materials science aspects of these mechanisms (see his extensive report given in $A n n$. Rev. Mat. Sci. 19, 1988).

One of the most intriguing mechanical phenomena in glassy polymers is the formation of crazes. This subject was treated in detail at the meeting and real breakthroughs were witnessed in the determination and interpretation of the fibrillation process introducing such new concepts as forced reptation (E.J. Kramer, Ithaca) and C.J. Plummer (Cambridge/UK), and stress induced sorption of otherwise non-compatible polymers (R.E. Cohen, Cambridge/Mass.). Most of the outstanding lectures of this day are published in a new volume of Advances in Polymer Science, Crazing in Polymers, Vol. 2, ed. H.H. Kausch, 1989). Another important subject is the fracture of polymers at low temperatures. As G. Gartwig (Karlsruhe) pointed out, at low temperatures the strength of a polymer increases whilst the fracture strain decreases. Most mechanical and thermal properties at very low temperatures are rather independent of chemical structure but depend on morphology, i.e. crystallinity or cross-linking. Unexpected, certainly, was that some polymers (PE) at $77 \mathrm{~K}$ become remarkably tougher at strain rates above $\dot{\varepsilon}=10^{3} \mathrm{~s}^{-1}$. On the third day of the conference, fracture, molecular structure and morphology were put into perspective. L.C.E. Struick (Geleen) chose the fracture mechanics approach and U.W. Gedde (Stockholm) a detailed analysis of the crystalline superstructure (including DSC and electron microscopy).

\section{Chemistry of Fracture}

Molecular fracture events were studied by F. Szöcs (Bratislava) using ESRtechnique; N.Ya. Rapoport (Moskow) drew attention to the generally neglected phenomenon that mechanical stresses can influence the kinetics of chemical reactions (e.g. the oxidation, leading to microcrack formation and subsequent, stress-dependent failure). She also pointed out the anisotropy of diffusion of low molecular weight radicals in stretched polymers - and thus the anisotropy of the propagation of the reaction.

In an attempt to elucidate the importance of the different molecular fracture mechanisms and exploiting the possibilities of a large chemistry laboratory, an exploring physicist, M. Fischer (Marly) had prepared networks with tailored distances, $L$, between crosslinking points. The critical crack opening in these materials turned out to be a constant multiple $(\cong 350$ ) of $L$; the fracture energy, however, was predominantly spent in the plastic deformation of the network up to such an extension.

J.T. Dickinson (Pullmann, Washington) discussed the application of fracto- 
emission analyses to determine failure processes in unfilled as well as filled epoxy resins. The technique can be used in a way similar to that of acoustic emission, but offers considerably greater flexibility and precision. The fractoemission technique has been applied to fibre-reinforced composites enabling the initial stages of matrix failure as well as fibre-matrix debonding to be assessed in detail.

\section{Ultra-highly Oriented Polymers}

Happily, almost all of the delegates managed to re-surface following the conference cruise and banquet in time for a series of presentations detailing the production and subsequent mechanical properties of highly oriented polymers and fibres. L.P. Majasnikova (Leningrad) employed a wide range of techniques in order to study the effect of varying the processing conditions on the morphology of ultra oriented polyethylene (UHMWPE). She proposed that the motion of extended chain segments is the limiting mechanism in fibres produced from this material. This hypothesis correlates well with the recent work of Pennings (Groningen) who stated that the stress-induced solid-solid phase transition occurs at higher temperatures.

P.J. Lemstra (Eindhoven) continued this theme by considering the feasibility of inducing crosslinks during the processing of polyethylene fibres. Induced chemical crosslinks via electron beam irradiation can help to reduce the rate of creep deformation in UHMWPE. However, care must be taken since radiation of the gel-spun fibres may precipitate chain scission and therefore lead to poorer rather than better mechanical properties. Consequently, it is suggested that crosslinking should be induced either before or during the initial stages of draw.

A. Zachariades (San José) discussed the relationship between the tensile properties and the molecular draw ratio of ultra-drawn UHMWPE in terms of the macrofibrillar dimensions. By developing a morphological model, the tensile properties of the polymer were predicted as a function of the fibrillar properties and dimensions; record values of fibre stiffness were reported -220 $\mathrm{GPa}$ at draw ratios of 200 to 300 . Such enormous values had become possible through a clever "unzipping procedure" of UHMWPE monocrystals.

D. Prevorsek (Morristown) assessed the compressive properties of polyethylene fibres and composites. Interestingly, he pointed out that molecules with small cross-sectional areas generally offer good tensile strengths but poor compressive properties. He suggested that the strength of these oriented fibres will depend strongly upon the fibril diameter, fibril spacing as well as the interfibrillar strength. It was suggested that the last point represents perhaps the most effective means of enhancing the compressive properties of these fibres. I.M. Ward (Leeds) examined creep and stress relaxation effects in ultra-high modulus polyethylene and showed that it is possible to model the creep response of this material using a two-part thermally-activated model. Detailed analyses such as this are greatly needed since the long-term load-carrying capability is still a great cause for concern.

The microhardness of polymeric materials was discussed in some detail by $F$. Balta-Calleja (Madrid). Here, it was shown that the hardness of a semi-crystalline polymer can be modelled using a simple parallel spring analysis taking account of the microhardness of the crystalline and amorphous regions. Using this type of analysis, it was possible to assess the influence of varying parameters such as the crystal thickness on the hardness properties of the polymer.

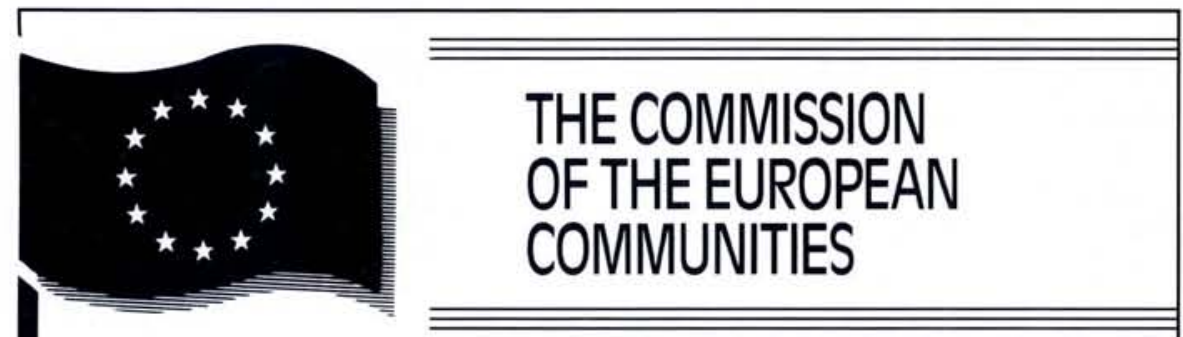

is carrying out a selection procedure with a view to drawing up a reserve list from which to appoint staff in grade $A 3$ for implementing the

\section{FUSION PROGRAMME (COM / R / A / 37) HEAD OF UNIT / ADVISER (grade A3)}

Duties: under the authority of the Director of the Fusion Programme, either:

$\square$ heading the unit responsible for coordinating Community research on the physics of fusion and for scientific and technical management of the Fusion Associations: $\square$ or coordinating the work involved in drawing up the Community's Fusion Programme and acting as its representative to other community Institutions (European Parliament, Council) and outside bodies.

Qualifications: University education with degree or diploma in a relevant discipline.

Experience: at least 15 years' work in controlled thermonuclear fusion or an associated field.

\section{GENERAL CONDITIONS}

Contracts: only temporary contracts of fixed or indefinite duration are offered to research staff. Nationality: candidates must be a national of one of the Community Member States. Place of employment: Commission staff must be available to work in any of the Commission's places of activity and in many cases outside their country of origin. Age: candidates must have been born after 1 June 1933. Knowledge of languages: candidates must have a thorough knowledge of one Community language (Danish, Dutch, English, French, German, Greek, Italian, Portuguese or Spanish) and a satisfactory knowledge of a second Community language. Closing date: requests for application forms must be made in writing not later than 15.5 .89 (postmark) to the following address: C.E.C., Secretariat for Selection committees Research, SDME R2 / 82, rue Montoyer 75, B-1040 Brussels (tel.: 02 / 235.56.60).

These application forms, duly completed and signed, must reach the above address not later than 6.6.1989.

Eligibility: candidates must ensure that: $\square$ the above deadlines are met; $\square$ their application form is legible, complete and signed; $\square$ copies of certificates and other documents specified in the application form are attached; $\square$ the other conditions set out above are satisfied, failing which they will be disqualified. The commission is an equal opportunities employer. 


\section{Blends and Composites}

The later stages of the conference dealt with distinct two phase materials with a number of talks on rubbertoughened as well as fibrous systems. C.B. Bucknall (Cranfield) talked on the principles and consequences of varying the size of the rubber particles on the fracture properties of toughened nylon. He found that at low strain rates, the size of the rubber particles did not influence the toughness of the polymer whereas at high rates of strain, matrices with larger particles tended to offer improved toughness. He also discussed the feasibility of adding thermoplastics to epoxy resins in order to enhance their fracture toughness. It was stated that the shortterm toughness of an epoxy can be increased by a factor of three by adding fifteen percent of poly-ether-imide.

Local activities were presented by W.J. Cantwell and A.C. Roulin-Moloney, who reported on the considerable experience of the Lausanne Laboratory in dealing with the fractographic analyses of pure and loaded resins in a wide range of strain rates and temperatures (see also Fractography and Failure Mechanisms of Polymers and Composites, ed. A.C. Roulin-Moloney (Elsevier Applied Science, Barking) 1989.

Two quite surprising conclusions were drawn from this multitude of data:

a) The total energy available within a specimen determines the fracture surface roughness;

b) A crack clearly needs some time and distance - in order to accelerate up to the limiting crack speed.

One of the most enlightening talks was given by R.J. Young (Manchester) on the subject of the application of Raman spectroscopy to the analysis of micro-deformation in single fibres. Here, it was shown that the technique can be used to determine the magnitude of shrinkage stresses in fibre-reinforced composite materials. This is of particular importance since thermal stresses are often a cause of the premature failure of laminated composites. Young and his colleagues were the first to determine experimentally the size of the critical transfer length in a high modulus fibre.

Another view into the future, the very promising subject of the behaviour of special three-phases composites, was treated by F.J. McGarry (Cambridge/ Mass.). The talk spanned in a short historical review the very first (and then unsuccessful) attempts of blending in the 40 s, the present role of a rubber phase in polymers, and that of rubbercoated glass and carbon fibres. Coating increases impact strengths by up to
8 -fold while diminishing only slightly (10 to $30 \%$ ) the transverse tensile strengths of the composites.

Important contributions to the conference also came from the 54 individual poster contributions. As an example, the invited paper on chain interdiffusion (M. Tirrell) was ably supported by six posters on the dynamics of entangled polymer melts, and on adhesion, knit line formation, welding and fracture of different polymers. Eight posters dealt with crazing, showing e.g. interesting computer simulations, explaining the toughening effect of rubber particles (through geometrical interaction of the particles beyond a critical filling ratio of between 6 and 17\%) or of ion-content (in sulfonated polystyrene).

The conference was a great success, attracting 180 participants from eighteen countries including the USA, Japan, Canada, Australia, Russia, and of course most European countries. It was accompanied by a well-received exhibition of relevant books from most of the pertinent polymer publishing companies featuring works on general polymer physics, chemistry, mechanics and processing as well as a special selection of books on polymer fracture.

Extended abstracts of all contributions are found in Europhysic Conference Abstracts, Vol. $12 \mathrm{~J}$ (1988).

\title{
ICFA Plots a New Course
}

\author{
W.O. Lock, CERN
}

The initial activities of ICFA, the International Committee for Future Accelerators, established in 1976 by the Particles and Fields Commission of the International Union of Pure and Applied Physics (IUPAP), revolved around the idea of a 'World Machine' [1]. However, to keep abreast of the changing world physics scene, in August 1985 its mandate was re-defined as:

- to promote international collaboration in all phases of the construction and exploitation of very high energy accelerators;

- to organize regular world-inclusive meetings to exchange information on future plans for regional facilities and to formulate advice on joint studies and uses;

- to organize workshops to study problems related to super high energy accelerator complexes and their international exploitation and to foster research and development of necessary technology.

\section{General ICFA Activities}

Following the second of the new IUPAP guidelines, ICFA organized a second "Future Perspectives in High Energy Physics" Seminar at the Brookhaven National Laboratory, USA, in October 1987. It attracted a wide attendance not only from the major high energy physics laboratories in eastern and western Europe, the USA, USSR and Japan but also from Argentina, Australia, Brazil, Canada, China, Mexico, Pakistan and South Korea [2]. The next
Seminar in the series will be held in the Soviet Union at the Serpukhov Institute of High Energy Physics in the spring or autumn of 1990. Although such meetings are clearly useful, especially with many developing countries becoming increasingly involved in different aspects of high energy and accelerator physics, they can do little more than serve as a forum for exchanging information and ideas. The active role of ICFA today is best mirrored in the work of the four specialist Panels, established after the 1984 Seminar [1].

\section{Panel on Future Instrumentation Inno- vation and Development}

The aims of this Panel are to create new channels of communication and to stimulate the involvement of all regions of the world in experimental high energy physics. In pursuance of these, the Panel has organized the ICFA Instrumentation School, the ICFA Instrumentation Bulletin, and the ICFA Review of Detector Properties.

The Instrumentation School teaches to Ph.D. students or young Ph.D.s the physics and technology of particle detectors and the experimental requirements of new and planned accelerator facilities. Hands-on laboratory exercises constitute an important part of the School. The aim is to have about equal participation from industrialized and developing countries. The first School was held at the International Centre for Theoretical Physics (ICTP) in Trieste, Italy in June 1987 and was attended by 